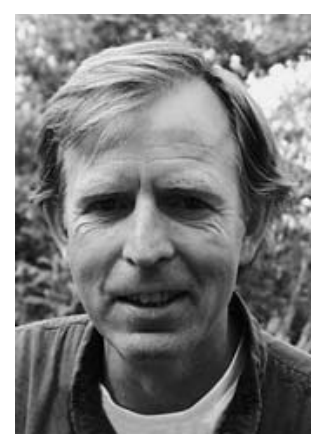

\title{
Genetic Apocrypha
}

If we look at the human genome and genetic material of diseasing agents as libraries full of information, infectious diseases can be regarded as a scholarly clash between scribes. A simple cold resembles a dispute concerning minor differences whereas a life-threatening disease can be compared to a religious war between orthodox faculties.

Our immune system defends the human genome as if it were the Holy Scripture and alien genetic material is dealt with as apocrypha, as they do contain a message that does not correspond to the truth as we see it.

The reality of the history of our genetic material is that $95 \%$ is said to stem from bacteria and viruses that somehow and somewhere in time managed to get their information included in the human genetic library. A lot of their "scriptures" are badly understood and derogatorily called junk DNA. One could say that they're in the Vatican but not acknowledged to contain a useful message for humanity: a fate I wouldn't doubt will change with time and certainly better than that of those that were burned on the stake.

A fast-forwarded replay of the history of the human genome would thus show a gradually expanding library. In the process it has been restructured innumerable times, new sections were added and other ones sank into oblivion. The whole library burned down many times but thanks to the many versions of it the continuing evolution of its content was never seriously jeopardised.

Parts of the human race that lived in isolation for long periods of time fell seriously ill from innocent childhood diseases, as did the Native American Indians who were practically decimated by the measles, while in return syphilis that was relatively harmless for them left deep scars in Europe.

The whole concept of infectious diseases is based on the delusion of separation, of "me" versus "not me", and no other outcome can be envisioned as that in time we will make peace with more and more microbes, find ways to live with them, and learn and benefit from them. Current epidemics are showing which lost parts of our potential unity are being retrieved and brought back to us so we can fulfil the higher purpose of our existence.

Death and infectious diseases, suffering and chronic miasmatic diseases: they are all part and parcel of this process. Microbes play their part and serve the human race by helping it to make the necessary evolutionary steps and do this in an impersonal way. They come where they are invited, flourish where conditions are favourable and leave when their purpose has been achieved.

Apart from the fact that the vast majority of genetic material in our body cells originates from microbes, the bacteria in and on our body also outnumber our cells. We can add to that the rapid replacement of all our bodily cells. Although the seven years it takes shows a slower rejuvenation than other tissues even bone is replaced. Each time atoms are replaced in a cell, changes in the DNA can occur. And then there is the effect of radiation and an ever-growing number of chemical substances present in our environment.

In this light the human genome is anything but a fixed entity, always changing and in constant communication with its surroundings. At the micro level also, the process of meeting strangers, of learning to accept their ways, of coming to respect their beliefs and finding a way to live with them in harmony is often a painful one. Epidemics take their toll and miasmatic diseases are like a bush fire that keeps smoking for a long time.

To suggest that homeopathy can change the outcome would imply that homeopaths know the course evolution has to take. However tempting this idea may be for the ego I suggest we denounce it as false. What we can offer is to reduce suffering by "the lifting and annihilation of the disease in its entire extent in the shortest, most reliable, and least disadvantageous way..." (Organon § 2). Not by killing the messenger or burning the message but by gratefully adding the scrolls to our library and living their wisdom.

Harry van der Zee, Editor 